\title{
ATMOSFERİK BASINÇLI PLAZMA UYGULAMASI İLE POLİPROPILEN MALZEMELERDE YÜZEY İŞLEMLERİ
}

\author{
Kadir AYAS \\ Zahide ÖZTAS KAPLAN \\ Kadir ÇAVDAR
}

Alınma: 02.08.2021; düzeltme: 01.11.2021; kabul: 01.11.2021

Öz: Maddenin dördüncü hali olan plazmayı kullanan atmosferik basınçlı plazma işlemi otomotivde boyanabilirlik ve yapışma, tekstilde nem tutma, hava geçirgenliği, ağırlık azaltma ve kir iticilik, gıdalarda bakteri inaktivasyonu ve tıpta iyileştirme hızlandırma gibi birçok alanda kullanılmaktadır. Atmosferik basınçlı plazmanın (ABP) polimerler üzerinde kullanılması yüzey modifikasyonu, yüzey aktivasyonu sağlaması, yüzey temizliği gibi avantajlara sahip olması, pek çok kombinasyonu olması ve parametrelerinin (güç, gaz akış debisi vb.) kontrolü ile beklenen özellikleri sağlaması nedeniyle önemli ve popülerliği artan bir konudur. Bu derleme çalışmasında atmosferik basınçlı plazma hakkında genel bilgiler verildikten sonra özellikle polipropilen (PP) malzeme üzerinde atmosferik basınçlı plazma yönteminin uygulamaları örneklenmiş ve benzer alanlarda yapılan çalışmalarla karşılaştırmalar yapılmıştır.

Anahtar Kelimeler: Atmosferik plazma, Polipropilen, Yüzey aktivasyonu, Plazma, Boyanabilirlik, Kaplama

\section{Application of Atmospheric Pressure Plasma on Polypropylene}

\begin{abstract}
Atmospheric pressure plasma treatment using plasma, which is the fourth state of matter, is used in many areas such as paintability and adhesion in automotive, moisture retention, air permeability, weight reduction and dirt repellency in textiles, bacterial inactivation in foods and acceleration of healing in medicine. Application of atmospheric pressure plasma (APP) on polymers is an important and increasing topic because it has advantages such as surface modification, surface activation, surface cleaning, has many combinations and provides the expected properties by controlling its parameters (power, gas flow rate, etc.). In this study, after giving general information about atmospheric pressure plasma, application of atmospheric pressure plasma especially on polypropylene (PP) material exemplified and comparisons are made with studies in similar fields.
\end{abstract}

Keywords: Atmospheric plasma, Polypropylene, Surface Activation, Plasma, Dyeability, Coating

\footnotetext{
" Bursa Uludağ Üniversitesi Fen Bilimleri Enstitüsü, Makine Mühendisliği ABD., 16059, Nilüfer, Bursa

** A-plas Genel Otomotiv Mamülleri San. ve Tic A.Ș., Osmangazi/Bursa

*** Bursa Uludağ Üniversitesi Mühendislik Fakültesi, Makine Mühendisliği Bölümü, 16059, Nilüfer, Bursa İletişim Yazarı: Kadir AYAS (kadirayas@uludag.edu.tr)
} 


\section{GİRIŞ}

Plazmanın geçmişi 18. yüzyıla dayanmaktadır. Terim olarak plazma ilk kez Nobel ödüllü Amerikalı kimyacı ve fizikçi Irving Langmuir tarafından kullanılmıştır (D'Agostino ve diğ., 2005). Plazma terim olarak farklı alanlarda farklı anlamlara gelmektedir. Fizik alanında plazma iyonize olmuş gaz anlamına gelmektedir. Irving Langmuir plazma ismini iyon, nötron, foton ve radikallerin kompleks karışımının kan plazmasındaki yapıya benzemesinden dolayı seçmiştir (Küçük ve diğ., 2018; Piel, 2010). Plazma ilk kez David A. Frank-Kamenezki tarafından maddenin dördüncü hali olarak tanımlanmıştır. Bu fikir Michael Faraday'a kadar uzanmaktadır. Faraday gazlarda akan elektrik akımlarının ürettiği ışıklı fenomenlerle ilişkilendirdiği maddenin parlak bir durumu hakkında maddenin farklı bir hali olduğu fikrini belirtmiştir (Piel, 2010).

Bir gaza (soy gaz, saf oksijen veya hava), uygun basınçta (düşük, atmosferik veya yüksek basınç), yüksek enerji verildiğinde (1s1, doğru akım veya alternatif akım kaynağı elektrik, elektromanyetik alan, radyo frekans dalgaları vs.) gaz molekülleri kinetik enerji kazanarak birbirleriyle çarpışmaya başlar. Bu çarpışmalar sonucunda elektronlar moleküllerden kopmaya başlar ve sürekli hareket halinde olan pozitif yüklü iyonların ve elektronların oluşturduğu bir sistem haline gelir. Maddenin bu durumuna plazma adı verilir (Küçük ve diğ., 2018).

Bilinen evrenin büyük çoğunluğu plazma halindedir. Plazmalar doğal fenomenler olarak pek çok formda görülebilmektedir. Güneşimiz de dahil olmak üzere yıldızlar ve yıldırımlar sıcak plazmalara örnek olurken, kuzey ışıkları (aura) doğada gözlemlenebilir soğuk plazmaya örnektir.

Yapay olarak üretilen plazmalar endüstrideki kullanım amacına bağlı olarak değişik basınçlar altında sıcak veya soğuk olarak üretilmektedir. Plazma teknolojileri sanayide de pek çok alanda kullanılmaktadır. Bunlardan bazıları plazma kesim ve kaynak, ergitme, plazma yüzey işlemleri (kaplama, temizleme, biriktirme vb.), mikroelektronik dağlama, elektronik yonga üretimi, floresan lamba, optik ve hatta uzay mühendisliğinde süpersonik yanmalı motorlardır (Gomez ve diğ., 2009; Massines ve diğ., 2001; Peretich ve diğ., 2007; Piel, 2010)

$\mathrm{Bu}$ çalışmada, atmosferik basınçlı plazma ile polipropilen malzemesi üzerinde yapılan çalışmalar derlenmiştir. Tablo 1'de incelenen konu başlıklarına ait makaleler belirtilmiştir. Polipropilen (PP) malzemesi hafiflik, yüksek termokimyasal dayanıklılık, kolay işlenebilirlik, geri dönüştürülebilirlik, üretim maliyetlerinin azlığı gibi nedenlerden dolayı otomotiv, uçak ve tekstil sanayilerinde dünya çapında tercih edilmektedir. Global ölçekte kullanılan bütün polimerlerin \%25-35 kadarını PP oluşturmaktadır (Esen ve diğ., 2016; Kehrer, Rottensteiner ve diğ., 2020). Ancak PP malzemesinin 1slanabilirliği düşüktür ve düşük yüzey enerjisine sahiptir

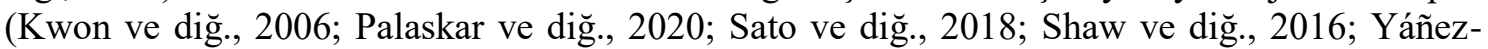
Pacios ve Martín-Martínez 2017). Özellikle $95^{\circ}-109^{\circ}$ slatma açısı ve $28 \mathrm{dyne} / \mathrm{cm}^{2}$ yüzey enerjisi nedeniyle boyama, yapışma ve kaplama gibi uygulamalarda problemler yaşanmaktadır (Esen ve diğ., 2016). Son zamanlarda adezyon problemini aşabilmek için pek çok yüzey işleme yöntemi geliştirilmiştir. $\mathrm{Bu}$ yöntemlerden bazıları mekanik aşındırma, kimyasal aşındırma, flame aktivasyonu, korona aktivasyonu ve atmosferik basınçlı plazma yüzey aktivasyonudur (Esen ve

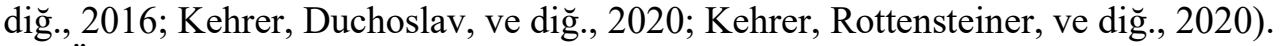

Özellikle atmosferik plazma yüzey işleme yöntemi çevreye zararlı olmaması, yüksek yüzey aktivasyonu, malzemenin mekanik özelliklerini etkilememesi bakımından gelecek vadeden bir yöntemdir (Esen ve di ğ., 2016; Kehrer, Duchoslav, ve diğ., 2020). Atmosferik plazmada çeşitli gazlar, gaz karışımları ve gaz-sıvı karışımları kullanılabilir, kızdırma deşarjı ve dielektrik bariyer deşarjı gibi plazma üretim yöntemleriyle farklı kombinasyonlar üstünde çalışılabilmektedir. Nitekim bu alanda pek çok çalışma yapılmıştır (Kehrer, Duchoslav, ve diğ., 2020; Prat ve diğ., 1998; Upadhyay ve diğ., 2004). 
Tablo 1. İncelenen konu başlıkları ve makaleler

\begin{tabular}{|c|c|}
\hline Makalenin Konusu & Çalışmalar \\
\hline $\begin{array}{l}\text { Atmosferik Plazma Yüzey } \\
\text { Aktivasyonu }\end{array}$ & 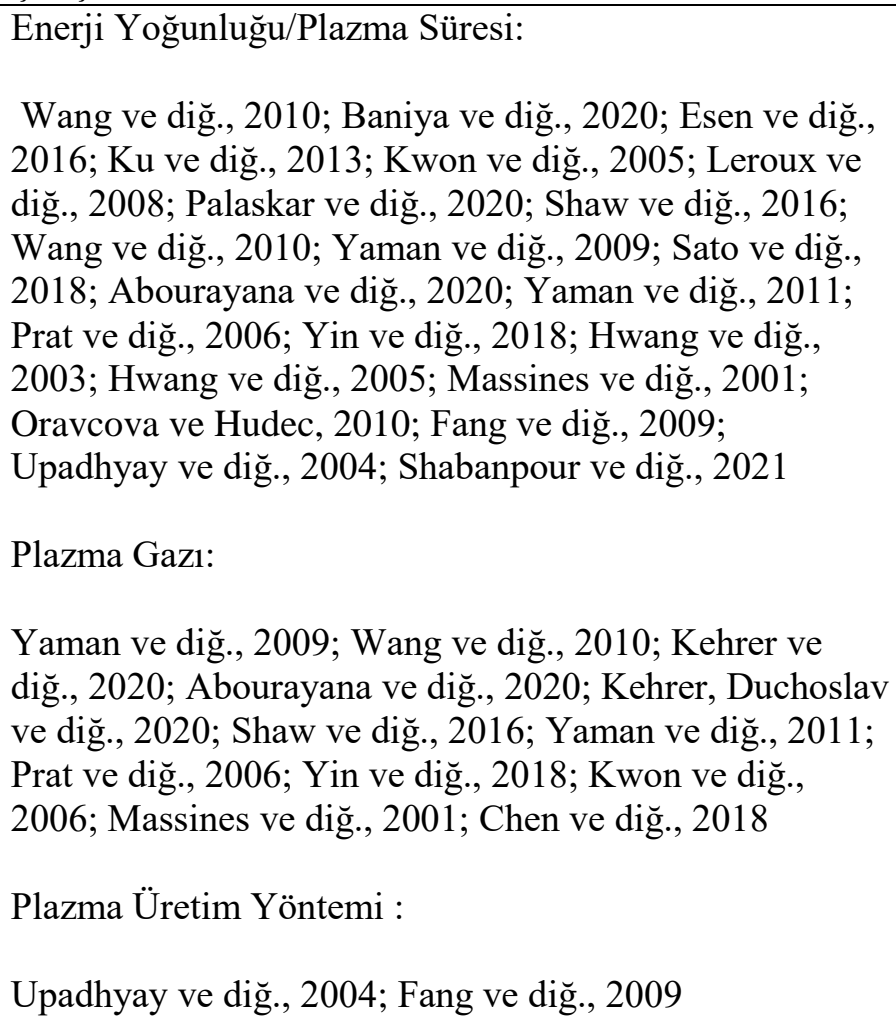 \\
\hline $\begin{array}{l}\text { Atmosferik Plazma Yüzey } \\
\text { Kaplama }\end{array}$ & 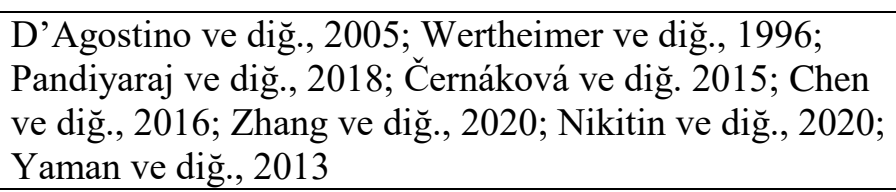 \\
\hline
\end{tabular}

\section{ATMOSFERİK BASINÇLI PLAZMA İLE YÜZEY İŞLEMLERİ}

\subsection{Yüzey Aktivasyonu Uygulamaları}

Çalışmalar göstermiştir ki sıcaklık karşısında hassas olan materyallerin işlenmesinde atmosferik basınçlı plazmalar uygun araçlar olabilmektedir. Çeşitli polimerlerin yüzeyinde farklı sonuçlar elde etmek için atmosferik plazma işlemleri yapılmaktadır. Daha iyi yapışma için yüzey aktivasyonu, yüzey temizliği, hidrofilik ya da hidrofobik özellik kazandırılması atmosferik plazma işleminin hedeflerinden bazılarıdır (Penkov ve diğ., 2015). Shabanpour ve diğ. (2021) yaptıkları çalışmada flame aktivasyonunu ve hava kullanan atmosferik plazma işlemini farklı modifikasyon sürelerince karşılaştırmışlardır. Bu çalışmada elde edilen sonuçlara göre optimize edilmiş atmosferik plazma işleminden sonra yüzeydeki N/C ve $\mathrm{O} / \mathrm{C}$ değerleri neredeyse iki katına çıkmıştır. Plazma işlemi sonrası yapılan boya işlemine yapılan basınçlı yıkama, asit dayanıklılığı ve cross-cutting testleri göstermiştir ki atmosferik basınçli plazma işlemi kendinden beklenen etkinliği göstermiştir.

Polipropilen malzemesi düşük yüzey enerjisine sahip olmasından dolayı boyama, yapışma problemleriyle karşılaşılmaktadır. Atmosferik basınçlı plazma işlemi yapılarak bu sorunun üstesinden gelmek mümkün olabilmektedir. Ancak değişen plazma kompozisyonlarından farklı verimler alınmaktadır. En uygun gaz karışım oranı, işlem süresi, plazma gücü, çalışma mesafesi 
Ayas K.,Öztaş Kaplan Z.,Çavdar K.:Atm. Basnçl.Plzm. Uyg. İle Poliprop. Malz. Yüzey İşleml.

vb. plazma parametrelerinin tespiti için çalışmalar yapılmıştır (Esen ve diğ., 2016; Kwon ve di 2006; Shaw ve diğ., 2016).

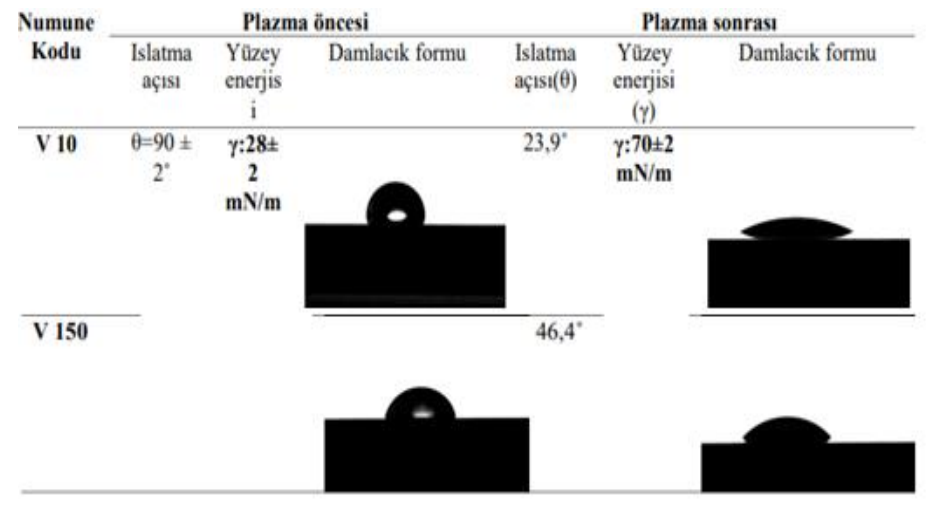

Sekil 1:

Sabit 5 mm mesafeden düşük ve yüksek hız aralığında plazma aktivasyon işlemi sonucunda yüzey ıslatma açısı ve yüzey enerjisi değişimi (Esen ve diğ., 2016)

Plazma enerjisi yoğunluğu $\left(\mathrm{J} / \mathrm{cm}^{3}\right)$ yüzey aktivasyonunun önemli parametrelerindendir. Enerji yoğunluğu, deşarj gücü ve arıtma süresinin çarpımının deşarj alanına bölünmesiyle hesaplanabilir (Wang ve diğ., 2010). Bu bakımdan plazma cihazının tarama hızı ya da plazma işlem süresinin yüzey aktivasyonuna etkisi büyüktür. Yapılan çalışmalarda artan plazma süresine bağlı olarak polipropilen yüzey enerjisinin \%300'e kadar artabildiği, su temas açılarında \%85 oranında düşüşler elde edildiği, yüzey pürüzlülüğünde artışlar görüldüğü belirtilmiştir (Şekil 1 ve 2). Bu aktivasyon seviyeleri plazma parametrelerinin kombinasyonuna göre değişiklik göstermektedir. Ayrıca bazı çalışmalarda yüzey enerjisi, plazma süresiyle doğru oranda artmakta ancak belirli sürelerden sonra yüzey enerjisi artış hızı düşmekte hatta sabit kalmaktadır (Baniya ve diğ., 2020; Esen ve diğ., 2016; Ku ve diğ., 2013; Kwon ve diğ., 2005; Leroux ve diğ., 2008; Oravcova ve Hudec, 2010; Palaskar ve diğ., 2020; Shaw ve diğ., 2016; Wang ve diğ., 2010; Yaman ve diğ., 2009). Bu durumda kullanılacak plazma cihazı ve parametrelerine göre ideal süreyi tayin etmek için çalışmalar yapmak gerekecektir. Şekil 1'de plazma cihazının düşük ve yüksek tarama hızlarında yüzey aktivasyonu öncesi ve sonrası yüzey enerjileri su temas açılarındaki değişim verilmiştir (Esen ve diğ., 2016). Şekil 3'te ise birden fazla kez yapılmış atmosferik basınçlı plazma işleminden sonra boya adezyon test sonuçları gösterilmiştir (Ku ve diğ., 2013). Bu çalışmalara göre plazma enerji yoğunluğun artışıla daha gelişmiş yüzey aktivasyonları elde etmek mümkündür.

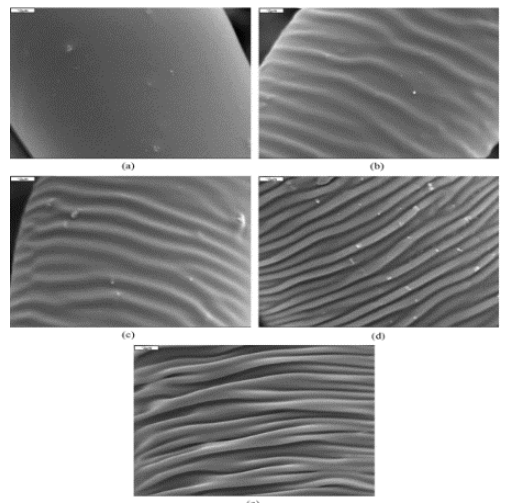

Sekil 2:

$\mathrm{He} / \mathrm{O}_{2}$ plazmast ile a) İ̧slem görmemiş b) $30 \mathrm{sn}$ c) 60 sn d) 90 sn e) 120 sn işlem görmüş $P P$ yüzeyleri taramalı elektron mikroskobu görüntüleri (Hwang ve diğ., 2005) 


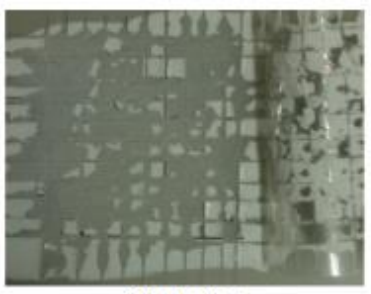

Untreated

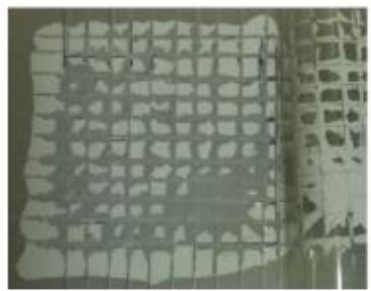

6 times

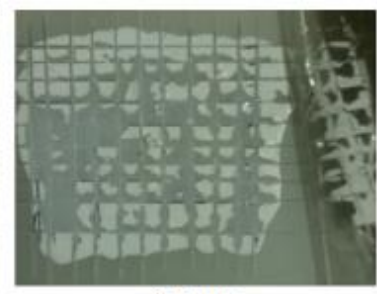

2 times

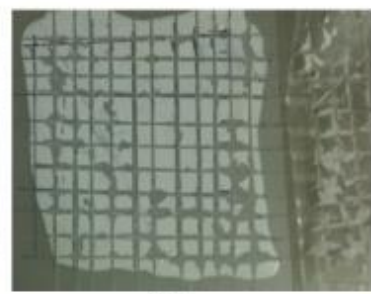

8 times

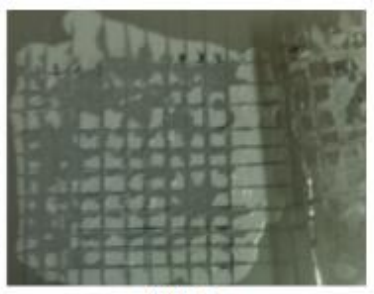

4 times

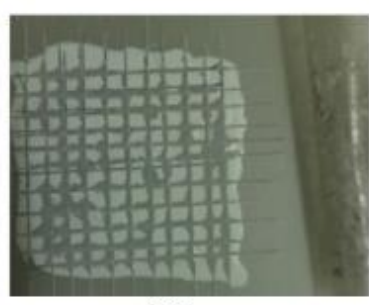

10 times

Şekil 3:

Birden fazla kez yapılmış atmosferik plazma işleminden sonra Al-PP kompozit yüzeyinde boya yapışma testi sonuçları (Ku ve dĭ̆., 2013)

Yüzey aktivasyonu ve 1slanabilirlikteki bir diğer önemli faktör, plazma işlemiyle yüzeyde oluşan kimyasal gruplardır. Atmosferik basınçlı plazma işlemi üzerine yapılan çalışmalar plazma sonrası su temas açılarındaki düşüş ve yüzeyde oluşan polar gruplar ile boyanabilirlik arasında bağlantı olduğu bulunmuştur (Encinas ve diğ., 2012; Hwang ve diğ., 2003, 2005; Jinka ve diğ.,

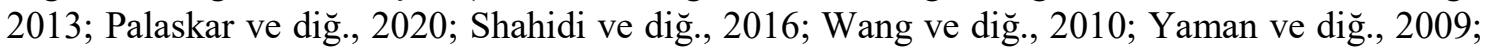
Yaman ve diğ., 2011). Bu çalışmalarda temas açısı üzerinde Argon gazının havaya (Yaman ve diğ. 2009), $\mathrm{N}_{2} / \mathrm{O}_{2}\left(\% 0,2 \mathrm{O}_{2}\right)$ karışımının saf $\mathrm{N}_{2}$ 'ye (Wang ve diğ., 2010) üstün oldukları rapor edilmiştir. Şekil 4 'te atmosferik basınc1 plazma işleminden önce ve sonra yüzeydeki kimyasal gruplar listelenmiştir (Encinas ve diğ. 2012)

\begin{tabular}{lll}
\hline Surface condition & $\begin{array}{l}\text { Binding } \\
\text { energy }(\mathrm{eV})\end{array}$ & Corresponding chemical group \\
\hline Untreated & 284.6 & {$[-(\mathrm{C}-\mathrm{C})-],[-(\mathrm{C}-\mathrm{H})-]$} \\
& 285.6 & {$[-(\mathrm{C}-\mathrm{N})-],[-(\mathrm{C}-\mathrm{OH})-]$} \\
& 399.7 & {$[-(\mathrm{R}-\mathrm{CN})-]$} \\
\multirow{3}{*}{ APPT } & 284.6 & {$[-(\mathrm{C}-\mathrm{C})-],[-(\mathrm{C}-\mathrm{H})-]$} \\
& 285.6 & {$[-(\mathrm{C}-\mathrm{N})-],[-(\mathrm{C}-\mathrm{OH})-]$} \\
& 287.7 & {$[-(\mathrm{CO} 2)-],[-(\mathrm{C}=\mathrm{O})-]$} \\
& 288.7 & {$[-(\mathrm{C}-\mathrm{C}(=\mathrm{O})-\mathrm{OH})-],[-(\mathrm{C}-\mathrm{C}(=\mathrm{O})-\mathrm{OR})-]$} \\
& 399.7 & {$[-(\mathrm{R}-\mathrm{CN})-]$} \\
& 401.6 & {$[-(\mathrm{N}-\mathrm{O})-]$} \\
\hline
\end{tabular}

Şekil 4:

Hem işlem görmemiş hem de ABP işlem görmüş PP'nin XPS tarama sonuçları (Encinas ve dig., 2011)

Polipropilen yüzeyinde oluşan amorf fazların ve fonksiyonel grupların yapışma ve 1slatılabilirlik üzerinde yüzey pürüzlülüğü, mekanik bağlanma veya kimyasal bağlanmadan daha etkili olduğu düşünülmektedir. Sato ve diğ. (2018) $\mathrm{N}_{2}$ gazı kullanarak yaptıkları atmosferik plazma işleminden sonra Raman saçılması kullanarak yaptıkları spektrum ölçümlerinde amorf yapılar oluştuğunu tespit etmişler ve tekrarlanan plazma işlemlerinden sonra bu yapılarda artış gözlemlemişlerdir. Ayrıca yüzeyde oluşan fonksiyonel gruplar ve yüzeyde oluştukları derinlikler tekrarlanan plazma işlemleri sonrasında artış göstermiştir. Bu bilgiler ışı̆̆ında amorf yapıların oluşması, fonksiyonel grupların artışı ve plazma işleminin süresiyle yapışma mukavemeti arasında bir ilişki olduğu belirtilmiştir. Yapılan benzer çalışmalarda bu sonuçlar doğrulanmıştır. 
Buna ek olarak $\mathrm{N}_{2} / \mathrm{O}_{2}, \mathrm{~N}_{2} /$ Hava, $\mathrm{N}_{2} / \mathrm{Su}$ buharı vb. karışımlarla yapılan atmosferik plazma işlemlerinde amorf yapılar ve fonksiyonel gruplar gaz karışımının oranına göre çeşitlilikler göstermiştir (Kehrer, Duchoslav, ve diğ., 2020; Kehrer, Rottensteiner, ve diğ., 2020; Massines ve diğ., 2001). Fang ve di ̆. (2009) hava kullanan atmosferik koşullardaki filament yapıda dielektrik bariyer deşarjı (DBD) ve düşük basınç koşullarındaki homojen DBD plazmalarının etkilerini karşılaştırmışlardır. Şekil 5'te yüzey modifikasyonu sırasında homojen DBD (a) ve filamanlı DBD (b) için ış1k yayımı görüntüleri verilmiştir. Şekil 6-a'da plazmaların yüzey enerjisine etkileri ve Şekil 6-b'de plazma işleminden sonra yaşlanma etkileri verilmiştir. Düşük basınçta çalışan homojen DBD plazmasının daha etkili olduğu belirtilmiştir.

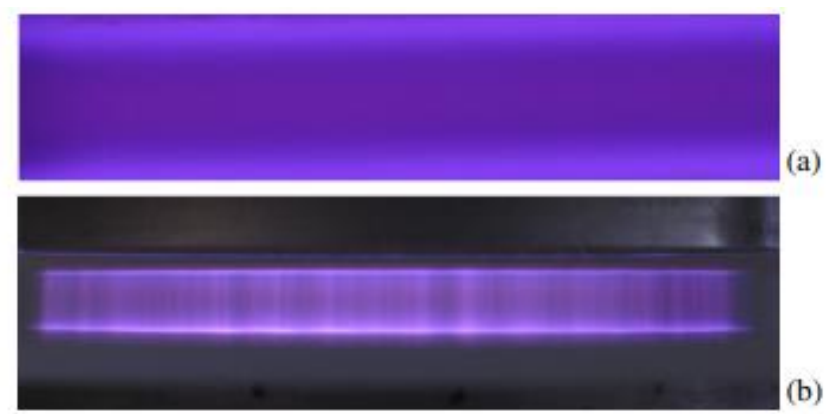

Sekil 5 .

Homojen DBD plazması (a) ve filamentli DBD plazması (b) yüzey modifikasyonu sırasında plazma görüntüleri (Fang ve diğ., 2009)

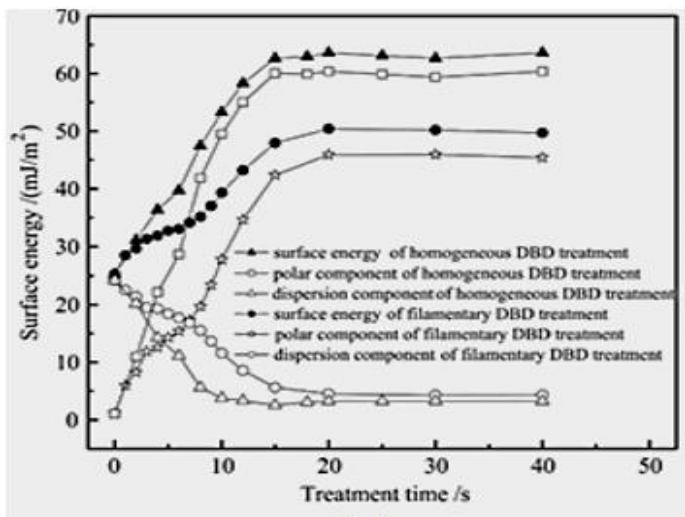

(a)

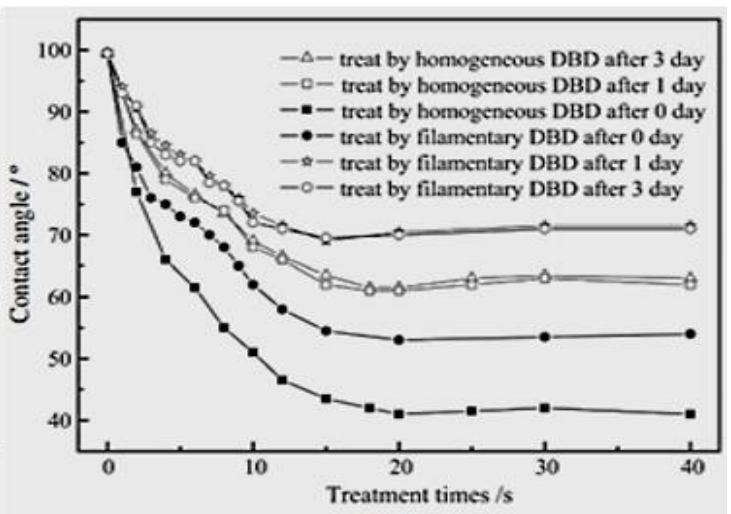

(b)

Şekil 6:

Plazma işleminde yüzey enerjisinin zamana bağll değişimi (a) ve temas açılarının zamana bă̆lı değişimi ve yaşlanması (b) (Fang ve diğ., 2009)

Atmosferik basınçlı plazma işlemi yaparken kullanılan gaz ya da gaz karışımlarının da önemli olduğu bilinmektedir. Argon plazma jetinin üretimi, nispeten daha ucuz, uygun ve kullanımı güvenli olan atmosferik koşullarda yapılabilmektedir. 30 saniyelik işlem sonunda su ve gliserol ile yapılan testlerde temas açılarında yaklaşık \%40 düşüş ve yüzey enerjisinde yaklaşık $\% 30$ artıș görülmektedir. İșlem süresinin daha da artması yüzey enerjisinde ve temas açılarında değişime neden olmamıştır. Plazma işlemi sırasında oluşan karbonil $(\mathrm{C}=\mathrm{O})$, hidroksil $(-\mathrm{OH})$, ve karboksil (-COOH) gruplarının yüzey enerjisinin artışında önemli etkileri olabilmektedir (Baniya ve diğ., 2020). Ayrıca plazma gücü ve gaz akış debisinin artması yüzeydeki polar ve apolar grupları artırmakta ve buna bağlı olarak yüzey enerjisinde artış görülebilmektedir (Kwon ve diğ., 2005). Kwon ve diğ. (2006) yaptıkları çalışmada argon gazına \%2'ye kadar oksijen eklemişler ve sonuçları incelemişlerdir. Yapılan çalışma saf Ar gazının $\mathrm{Ar} / \mathrm{O}_{2}$ karışımından daha iyi sonuçlar 
verdiği görülmüş fakat $\mathrm{O}_{2}$ oranının $\% 2$ ile kısıtlı olmasından dolayı daha fazla araştırma yapılması gerektiğini belirtmişlerdir.

Polipropilen malzemesi en hafif liflere sahip olması, güçlü ve esnek olması, düşük maliyetli olması özellikleri sebebiyle tekstilde tercih edilmektedir. Buna karşın oksitlenmeye karşı dayanıksızdır ve boyanması için ek işlem gerektirir, bu yüzden kaplama, dolgu gibi proseslerle dayanımı artırılır ve boyanabilmesi için çeşitli kimyasal işlemlerden geçer (Palaskar ve diğ., 2020; Shahidi ve diğ., 2016). Atmosferik plazma ile tekstil ürünlerinden beklenen hava geçirgenliği, boyanabilirlik, gerilme direnci, antibakteriyel aktivite, kir iticilik, su ve aşınma direnci vb. özelliklerde artış elde etmek mümkündür.

Tekstil ürünlerinde vücuttan çıkan nem ve ssının uzaklaştııılması kişisel konfor için önemli bir unsurdur. Ayrıca kumaşın ömrünün kısalmaması için gereklidir. Jinka ve diğg. (2013) yaptıkları çalışmada \%90 nitrojen ve $\% 10$ oksijen karışımı kullanan dielektrik bariyer deşarjı plazmasıyla PP kumaşın nefes alabilirliğini \%95 artırmışlardır. Hava geçirgenliğindeki artış plazma süresini artırarak daha da geliştirilebilmektedir (Hwang ve diğ., 2005).

Atmosferik plazma yüzey işlemi ile tekstil ürünlerinde maksimum çekme, basma, kayma, eğilme gerilmeleri gibi mekanik özelliklerde iyileştirmeler görülmüştür. Hwang ve diğ. (2005) 30, 60, 90, 120 saniye atmosferik plazma işlemi görmüş yüzeylerde ağırlıkta azalmalar tespit ederken, 0-60 saniye arası plazma işleminden sonra mekanik özelliklerde artış, 60-120 saniye arasında gerileme olduğunu raporlamışlardır. Polipropilenin mekanik özelliklerinde yapılan diğer çalışmalarda da atmosferik plazmanın etkinliğini kanıtlar sonuçlar elde edilmiştir (Hwang ve diğ., 2003; Palaskar ve diğ., 2020; Shahidi ve diğ., 2016).

\subsection{Yüzey Kaplama Uygulamaları}

Atmosferik plazma kaplama işlemi metaller, kumaşlar, polimerler gibi pek çok malzemeye yüzey sertleştirme, antibakteriyel aktivasyon, kit iticilik vb. özellikler kazandırmak amacıyla yapılmaktadır. Atmosferik plazma yerine kullanılabilecek geleneksel yöntemler bulunsa da çevreye zararlı olmaları ve homojen kaplama yapılamamasından dolayı plazma teknolojisine olan ilgi artmıştır (D’Agostino ve diğ., 2005; Wertheimer ve diğ., 1996).

Yüksek mukavemet, ucuzluk, kimyasal dirençleri nedeniyle polietilen, polipropilen vb. polimerler lityom-iyon bataryalarda ayırıcı malzeme olarak kullanılmaktadır. Ancak düşük 1slatılabilirlik özelliklerinden dolayı bu malzemeler bünyelerinde bulundurdukları sıv1-elektrolit azdır. Bu da lityum-iyon bataryalarda düşük elektrokimyasal aktiviteye sebep olarak performansı düşürmektedir. Chen ve diğ. (2018), atmosferik plazma uygulamasında $\mathrm{Ar} / \mathrm{O}_{2}$ ve $\mathrm{He} / \mathrm{O}_{2}$ karışımları ile polipropilen yüzeylerine akrilik asit aşılaması yapmışlardır. Yaptıkları bu uygulama sonucunda polipropilen s1v1 absorbsiyon miktarında \%300'e varan artış elde etmiş̧erdir ve bu sayede lityum-iyon batarya performansında iyileşme elde etmişlerdir. Bunun yanı sıra akma mukavemetinde düşüş görülse de kopmadan önce yüzdece uzama miktarı plazma uygulama süresine bağlı olarak \%70 seviyesinden \%140'a ulaşabildiği bulunmuştur. Taramalı elektron mikroskobu ve atomik kuvvet mikroskobu görüntülemeleriyle plazma işlem süresiyle değişen yüzey pürüzlülüğü artışı tespit edilmiş ve su temas açılarında azalma olduğu belirtilmiştir.

Polipropilen malzemesi otomotivde mekanik özelliklerinden dolayı kullanılan bir parça olsa da tıpta da kullanılmaktadır. Stentler, kalp kapakçıkları, kan damarları, hemodiyaliz bileşenleri ve kan torbaları polipropilenden üretilmektedir. Ancak polipropilen malzemesinin protein adsorbsiyonu, kandaki belirli yapıları yüzeyinde biriktirmesi medikal uygulamalar için engel teşkil etmektedir. Pandiyaraj ve diğ. (2018) polipropilen yüzeylerini atmosferik plazma yardımıyla etilen glikol dimetil eter monomeri kullanarak polietilen oksit benzeri kaplama yapmışlardır. Gaz akış debisi ve gerilimi $(\mathrm{kV})$ değiştirerek yaptıkları deneyler sonucunda C-O fonksiyonel gruplarının oluşumuyla polietilen oksit tabakasının kirlenme önleyici özelliği arasında bağlantı olduğunu belirtmişlerdir. Plazma gücündeki artışla yüzey pürüzlülüğünün arttığı, ancak aynı gerilim güçlerinde yüksek gaz debisi kullanan plazmanın etkinliği düştüğü görülmüştür. 
Polipropilen dokumasız kumaşlarında antibakteriyel etkinlik özelliği yapılan kaplamalar ile sağlanmaktadır. Černáková ve diğ. (2015) polipropilen dokumasız kumaşı (nonwoven) iyi bir adsorbent olan kitosan hammaddesiyle atmosferik plazma kullanarak kaplamışlardır. Atmosferik plazamda hava nitrojen gazlarını kullanmışlardır. Kitosan hammaddesi genellikle kabuklu deniz canlılarından elde edilen toksik olmayan organik bir malzemedir ve yapısında azot grupları bulunmaktadır. Bu çalışmaya göre nitrojen ile yapılan atmosferik plazma işlemi daha iyi sonuç vermektedir. Nitrojenin etkinliği polipropilen nonwoven üzerinde oluşan fonksiyonel gruplar ile kitosan arasında amit bağlarından ileri geldiği tahmin edilmektedir. Ayrıca kitosan sayesinde bakteri oluşumu azalmaktadır ve kitosanın adsorbent özelliği sayesinde boyanabilirliği artmaktadır (Şekil 7).
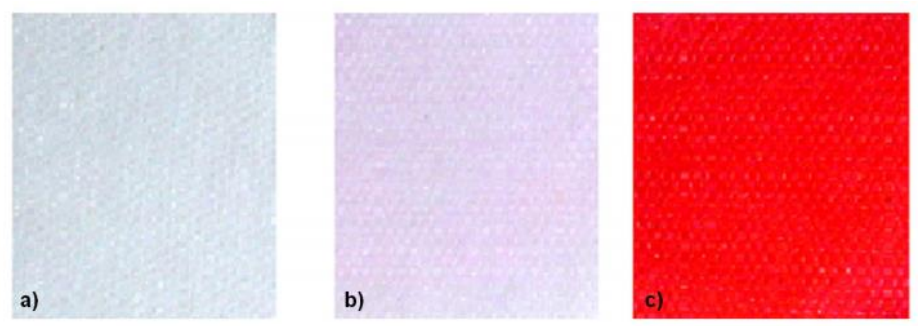

Sekil 7:

Polipropilen dokumasız kumaşın boyanması a) İ̧slem görmemiş, b) Plazmadan sonra, c) Plazma ve kitosan kaplanmasından sonra (Černáková ve diğ., 2015)

Nikitin ve diğ. (2020) polipropilen filmleri üzerinde kitosan daldırma ve hava kullanan atmosferik plazma kombinasyonu ile kitosan immobilizasyonu gerçekleştirmişlerdir. Bu kombinasyon ile yüzeyde hasar oluşturmadan kitosan immobilizasyonu sağlamışlardır. Plazma işlemi yapılan yüzeylerde pürüzlülükte artış tespit edilmiş, yapılan su temas açısı testlerinde de 1slatılabilirlikte artış olduğu belirtilmiştir. X-ray fotoelektron spektropisi analizleri ve elde edilen taramalı elektron mikroskobu görüntülerinde kitosan immobilizasyonunun başarılı olduğunu gösteren bulgular olduğuna değinmişlerdir.

Bir başka çalışmada Yaman ve diğ. (2013) polipropilen dokumasız kumaşların katyonik boyar maddeler ile boyanmasına atmosferik plazma, aşılama polimerizasyonu ve plazma indüklemeli polimerizasyonun etkilerini incelemişlerdir. Aşılamada akrilik asit, 6aminohekzanoik asit ve hekzametil disiloksan monomerleri ve hava plazması kullanarak yaptıkları çalışmada farklı karışım konsantrasyonları ve plazma gücü kullanarak 3 farklı renk katyonik boyar maddenin kumaşa işlediği derinliğini ölçmüşlerdir. Buna göre boya derinliğinde en iyi sonuçları $130 \mathrm{~W}$ gücünde plazma indüklemeli polimerizasyon yöntemiyle elde etmişlerdir.

Biyomedikal uygulamalarda gösterdiği uyumluluk, düşük toksik özellikleri ve çevresindeki dokuyu uyarabilmesinden dolayı PP filmler tercih edilmektedir. PP'nin gösterdiği düşük ıslanabilirlik ve yapışma direncini geliştirmek ve başka özellikler eklemek amacıyla farklı kaplamalar yapılmaktadır. Pandiyaraj ve diğ. (2019) argon gazı kullanarak yaptıkları çalışmada PP filmlerini farklı gerilimler ve monomer akış debisi kullanarak yüzeydeki fosfor birikimini incelemişlerdir. Artan gerilim ve akış debisiyle su temas açılarında düşüş, yüzey pürüzlülüğünde artış tespit edilmiştir. Yapılan benzer çalışmalarda temas açısı ve yüzey pürüzlülügü̈ndeki değişimler doğrulanmıştır (Chen ve diğ., 2016; Zhang ve diğ., 2020).

\section{SONUÇ}

Atmosferik basınçlı plazma işlemi karakteristik olarak yüzey aktivasyonu sağlaması ve adezyon enerjisini artırmasıyla bilinmektedir. Bu çalışmada, atmosferik plazma ile yüzey işlemleri çalışmaları derlenmiştir. Literatürdeki çalışmalarda atmosferik basınçlı plazma uygulamasının yüzey aktivasyonu üzerindeki etkinliği kanıtlanmıştır. Fakat en yüksek verimle atmosferik plazma işleminden faydalanmak için farklı plazma üretim tekniklerinin (Dielektrik 
Bariyer Deşarjı, Radyo Frekans, Kızdırma Deşarjı vb.) etkinliği üzerine karşılaştırma yapıllmasına ihtiyaç vardır. Atmosferik basınçlı plazma işleminin nitelikli kullanımı için her bir plazma öğesinin (güç, voltaj, gaz, 1s1, süre vb.) birlikte kullanıldıklarında pozitif ve negatif etkinliklerinin de bilinmesi gereklidir.

Çalışmalar göstermiştir ki ABP işlemi görmüş PP yüzeylerinde polar grupların oluşması ve yüzey pürüzlülüğünün artmasına bağlı olarak ıslatılabilirlikte artış olmaktadır. Bu artışı, gaz akış debisi, plazma gücü, işlem süresi, çalışma mesafesi gibi parametrelerin kısıtlamasıyla belirli bir değeri aşamadığı durumlar olduğu görülmüştür. Atmosferik basınçlı plazma işleminden sonra yüzeyde oluşan bu etkilerin yanında malzemeyi oluşturan atomların yüzdece miktarları değişmektedir. Bu derleme çalışmasında incelenen yayınlarda görülen ortak sonuç atmosferik basınçlı plazma işlemi gören yüzeylerde kullanılan gaz çeşidi veya karışımına göre $\% \mathrm{C}$ miktarı düşerken $\% \mathrm{O}$ ve $\% \mathrm{~N}$ miktarı artış göstermektedir.

$\mathrm{Bu}$ derleme çalışmasında ele alınan araştırmalar göstermektedir ki atmosferik basınçlı plazma işlemi PP malzemesi özelinde tıp, tekstil, otomotiv, havacılık ve uzay sanayiinde çokça kullanılmaktadır. Seri üretime uygunluğu, düşük basınçlı veya yüksek basınçlı plazma işlemlerine göre düşük maliyeti ve sistem kolaylığı, sağladığı yüzey aktivasyonu ve diğer avantajlar sayesinde atmosferik basıç̧lı plazma işlemi özellikle PP malzeme grubunda etkili bir uygulamadır. Farklı malzemeler için boyama ve yapıştırma konularında daha fazla deneysel araştırmalara ihtiyaç duyulmaktadır. Farklı malzemelerin (metal + polimer gibi) yapıştırılmasında da deneysel çalışmalar oldukça azdır.

\section{ÇIKAR ÇATIŞMASI}

Yazarlar, bilinen herhangi bir çıkar çatışması veya herhangi bir kurum/kuruluş ya da kişi ile ortak çıkar bulunmadığını onaylamaktadırlar.

\section{YAZAR KATKISI}

Kadir ÇAVDAR çalışmanın kavramsal ve tasarım süreçlerinin belirlenmesi ve yönetimi, Kadir AYAS veri toplama ve veri analizi, Zahide ÖZTAŞ KAPLAN veri analizi ve yorumlamada katkı sağlamıştır.

\section{TEŞEKKÜR}

Bu çalışmada yer alan iki bursiyer, TÜBİTAK BİDEB (Türkiye Bilimsel ve Teknolojik Araştırma Kurumu Bilim İnsanı Destekleme Daire Başkanlığı) tarafından desteklenmiştir (Proje No: 119C206).

\section{KAYNAKLAR}

1. Baniya, H. B., Guragain, R. P., Baniya, B. ve Subedi, D. P. (2020) Cold Atmospheric Pressure Plasma Jet for the Improvement of Wettability of Polypropylene, International Journal of Polymer Science, 2020. https://doi.org/10.1155/2020/3860259

2. Černáková, L., Černák, M., Tóth, A., Mikulášová, M., Tomašková, M. ve Kováčik, D. (2015) Chitosan immobilization to the polypropylene nonwoven after activation in atmospheric Pressure Nitrogen Plasma, Open Chemistry, 13(1), 457-466. https://doi.org/10.1515/chem2015-0055

3. Chen, G., Yin, M., Huang, J., Yu, J., Qu, S., Wang, X. ve Li, C. (2018) The polypropylene membran modified by an atmospheric pressure plasma jet as a seperator for lithium-ion button battery, Electrochimia Acta, 260 (2018), 489-497. https://doi.org/10.1016/j.electacta. 2017.12.119 
4. Chen, W. X., Yu, J. S., Hu, W. ve Chen, G. L. (2016) Partial hydrophilic modification of biaxially oriented polypropylene film by an atmospheric pressure plasma jet with the allylamine monomer, Applied Surface Science, 387, 957-964. https://doi.org/10.1016/j.apsusc.2016.07.043

5. D’Agostino, R., Favia, P., Oehr, C. ve Wertheimer, M. R. (2005) Low-temperature plasma processing of materials: Past, present, and future, Plasma Processes and Polymers, 2(1), 7 15. https://doi.org/10.1002/ppap.200400074

6. Encinas, N., Abenojar, J. ve Martínez, M. A. (2012) Development of improved polypropylene adhesive bonding by abrasion and atmospheric plasma surface modifications, International Journal of Adhesion and Adhesives, 33, 1-6. https://doi.org/10.1016/j.ijadhadh.2011.10.002

7. Esen, S. G., Altuncu, E., Üstel, F. ve Akpınar, S. (2016) Different plasma scannıng velocities effect on surface wettability properties of polypropylene by atmospheric plasma surface activation, Sakarya Üniversitesi Fen Bilimleri Dergisi, 307-316.

8. Fang, Z., Xie, X., Li, J., Yang, H., Qiu, Y. ve Kuffel, E. (2009) Comparison of surface modification of polypropylene film by filamentary DBD at atmospheric pressure and homogeneous DBD at medium pressure in air, Journal of Physics D: Applied Physics, 42(8). https://doi.org/10.1088/0022-3727/42/8/085204

9. Gomez, E., Rani, D. A., Cheeseman, C. R., Deegan, D., Wise, M. ve Boccaccini, A. R. (2009) Thermal plasma technology for the treatment of wastes: A critical review, Journal of Hazardous Materials, 161(2-3), 614-626. https://doi.org/10.1016/j.jhazmat.2008.04.017

10. Hwang, Y. J., An, J. S., McCord, M. G., Park, S. W. ve Kang, B. C. (2003) The effect of etching on low-stress mechanical properties of polypropylene fabrics under helium/oxygen atmospheric pressure plasma, Fibers and Polymers, 4(4), 145-150. https://doi.org/10.1007/BF02908270

11. Hwang, Y. J., Mccord, M. G., an, J. S., Kang, B. C. ve Park, S. W. (2005) Effects of Helium Atmospheric Pressure Plasma Treatment on Low-Stress Mechanical Properties of Polypropylene Nonwoven Fabrics, Textile Research Journal, 75(11), 771-778. https://doi.org/10.1177/0040517505053805

12. Jinka, S., Behrens, R., Korzeniewski, C., Singh, V., Arunachalam, A., Parameswaran, S. ve Ramkumar, S. (2013) Atmospheric pressure plasma treatment and breathability of polypropylene nonwoven fabric, Journal of Industrial Textiles, 42(4), 501-514. https://doi.org/10.1177/1528083712464257

13. Kehrer, M., Duchoslav, J., Hinterreiter, A., Mehic, A., Stehrer, T. ve Stifter, D. (2020), Surface functionalization of polypropylene using a cold atmospheric pressure plasma jet with gas water mixtures, Surface and Coatings Technology, 384, 125170. https://doi.org/10.1016/j.surfcoat.2019.125170

14. Kehrer, M., Rottensteiner, A., Hartl, W., Duchoslav, J., Thomas, S. ve Stifter, D. (2020) Cold atmospheric pressure plasma treatment for adhesion improvement on polypropylene surfaces, $\begin{array}{lllll}\text { Surface and Coatings Technology, } 126389 . & \end{array}$ https://doi.org/10.1016/j.surfcoat.2020.126389

15. Ku, J. H., Jung, I. H., Rhee, K. Y. ve Park, S. J. (2013) Atmospheric pressure plasma treatment of polypropylene to improve the bonding strength of polypropylene/aluminum composites, Composites Part B: Engineering, 45(1), 1282-1287. https://doi.org/10.1016/j.compositesb. 2012.06.016

16. Kwon, O. J., Myung, S. W., Lee, C. S. ve Choi, H. S. (2006) Comparison of the surface characteristics of polypropylene films treated by $\mathrm{Ar}$ and mixed gas $(\mathrm{Ar} / \mathrm{O} 2)$ atmospheric 
pressure plasma, Journal of Colloid and Interface Science, 295(2), 409-416. https://doi.org/10.1016/j.jcis.2005.11.007

17. Kwon, O. J., Tang, S., Myung, S. W., Lu, N. ve Choi, H. S. (2005) Surface characteristics of polypropylene film treated by an atmospheric pressure plasma, Surface and Coatings Technology, 192(1), 1-10. https://doi.org/10.1016/j.surfcoat.2004.09.018

18. Leroux, F., Campagne, C., Perwuelz, A. ve Gengembre, L. (2008) Polypropylene film chemical and physical modifications by dielectric barrier discharge plasma treatment at atmospheric pressure, Journal of Colloid and Interface Science, 328(2), 412-420. https://doi.org/10.1016/j.jcis.2008.09.062

19. Massines, F., Gouda, G., Gherardi, N., Duran, M. ve Croquesel, E. (2001) The role of dielectric barrier discharge atmosphere and physics on polypropylene surface treatment, Plasmas and Polymers, 6(1-2), 35-49. https://doi.org/10.1023/A:1011365306501

20. Nikitin, D., Lipatova, I., Naumova, I., Sirotkin, N., Pleskunov, P., Krakovsý, I., Khalakhan, I., Choukourov, A., Titov, V. ve Agafonov, A. (2020) Immobilization of chitosan onto polypropylene foil via air/solution atmospheric pressure plasma afterglow treatment, Plasma Chemistry and Plasma Processing, 40:207-220. https://doi.org/10.1007/s11090-019-100292

21. Oravcova, A., \& Hudec, I. (2010) The influence of atmospheric pressure plasma treatment on surface properties of polypropylene films, Acta Chimica Slovaca, 3(2), 57-62.

22. Palaskar, S. S., Kale, R. D. ve Deshmukh, R. R. (2020) Application of atmospheric pressure plasma for adhesion improvement in polyurethane coating on polypropylene fabrics, Journal of Coatings Technology and Research, 17(2), 485-501. https://doi.org/10.1007/s11998-01900300-8

23. Pandiyaraj, K. N., Arun Kumar, A., RamKumar, M. C., Padmanabhan, P. V. A., Trimukhe, A. M., Deshmukh, R. R. ve Jaganathan, S. K. (2018) Influence of operating parameters on development of polyethylene oxide-like coatings on the surfaces of polypropylene films by atmospheric pressure cold plasma jet-assisted polymerization to enhance their antifouling properties, Journal of Physics and Chemistry of Solids, 123(June), 76-86. https://doi.org/10.1016/j.jpcs.2018.06.007

24. Penkov, O. V., Khadem, M., Lim, W. S. ve Kim, D. E. (2015) A review of recent applications of atmospheric pressure plasma jets for materials processing, Journal of Coatings Technology and Research, 12(2), 225-235. https://doi.org/10.1007/s11998-014-9638-z

25. Peretich, M. A., Brien, W. F. O. ve Schetz, J. A. (2007) Plasma Torch Power Control for Scramjet Application, Lisans Tezi, Virginia Polytechnic Institute and State University, Virginia.

26. Piel, A. (2010), Plasma Physics: An Introduction to Laborotory, Space and Fusion Plasmas, Springer-Verlag, Heidelberg.

27. Prat, R., Suwa, T., Kogoma, M. ve Okazaki, S. (1998) Adhesive Strength Study and Surface Analysis Using Gas-Phase Chemical Reactions of Atmospheric Pressure Plasma-treated Polypropylene, Journal of Adhesion, 66(1-4), 163-182. https://doi.org/10.1080/ 00218469808009964

28. Sato, T., Akiyama, H., Horiuchi, S. ve Miyamae, T. (2018) Characterization of the polypropylene surface after atmospheric pressure N2 plasma irradiation, Surface Science, 677(April), 93-98. https://doi.org/10.1016/j.susc.2018.06.010

29. Shabanpour, M., Mohammadhosseini, B., Khani, M. R., Khanjani, J., Shokri, B. ve Ghassami, 
Ayas K.,Öztaş Kaplan Z., Çavdar K.:Atm. Basnçl.Plzm. Uyg. Ille Poliprop. Malz. Yüzey İşleml.

A. (2021) Flame versus air atmospheric gliding arc plasma treatment of polypropylene-based automotive bumpers: Physicochemical characterization and investigation of coating properties, Polymer Engineering and Science, 61(5), 1581-1593. https://doi.org/10.1002/pen.25682

30. Shahidi, S., Ghoranneviss, M., Ilali, R., Karami, M. ve Miladi, M. (2016) Dyeing properties of the atmospheric pressure plasma-treated polypropylene fabric subjected to butane tetra carboxylic acid, Journal of the Textile Institute, 107(5), 636-644. https://doi.org/10.1080/00405000.2015.1054210

31. Shaw, D., West, A., Bredin, J. ve Wagenaars, E. (2016) Mechanisms behind surface modification of polypropylene film using an atmospheric-pressure plasma jet, Plasma Sources Science and Technology, 25(6). https://doi.org/10.1088/0963-0252/25/6/065018

32. Upadhyay, D. J., Cui, N. Y., Anderson, C. A. ve Brown, N. M. D. (2004) Surface oxygenation of polypropylene using an air dielectric barrier discharge: The effect of different electrodeplaten combinations, Applied Surface Science, 229(1-4), 352-364. https://doi.org/10.1016/j.apsusc.2004.02.012

33. Wang, K., Wang, W., Yang, D., Huo, Y. ve Wang, D. (2010) Surface modification of polypropylene non-woven fabric using atmospheric nitrogen dielectric barrier discharge plasma, Applied Surface Science, 256(22), 6859-6864. https://doi.org/10.1016/ j.apsusc.2010.04.101

34. Wertheimer, M. R., Thomas, H. R., Perri, M. J., Klemberg-Sapieha, J. E. ve Martinu, L. (1996) Plasmas and polymers: From laboratory to large scale commercialization. Pure and Applied Chemistry, 68(5), 1047-1053. https://doi.org/10.1351/pac199668051047

35. Yaman, N., Özdogan, E., Kocum, I. C., Ayhan, H., Öktem, T. ve Seventekin, N. (2009) Improvement surface properties of polypropylene and polyester fabrics by glow discharge plasma system under atmospheric condition, Tekstil ve Konfeksiyon, 19(1), 45-51.

36. Yaman, N., Özdoğan, E. ve Seventekin, N. (2013) Effect of Surrounded Air Atmospheric Plasma Treatment on Polypropylene Dyeability Using Cationic Dyestuffs, Fibers and Polymers 2013, 14(9), 1472-1477. https://doi.org/10.1007/s12221-013-1472-x

37. Yaman, N., Özdoğan, E. ve Seventekin, N. (2011) Atmospheric plasma treatment of polypropylene fabric for improved dyeability with insoluble textile dyestuff, Fibers and Polymers, 12(1), 35-41. https://doi.org/10.1007/s12221-011-0035-2

38. Yáñez-Pacios, A. J. ve Martín-Martínez, J. M. (2017) Surface modification and improved adhesion of wood-plastic composites (WPCs) made with different polymers by treatment with atmospheric pressure rotating plasma jet, International Journal of Adhesion and Adhesives, 77, 204-213. https://doi.org/10.1016/j.ijadhadh.2017.06.001

39. Zhang, P., Zhang, S., Kong, F., Zhang, C., Dong, P., Yan, P. ve Shao, T. (2020) Atmosphericpressure plasma jet deposition of bumpy coating improves polypropylene surface flashover performance in vacuum, Surface and Coatings Technology. https://doi.org/10.1016/j.surfcoat.2020.125511 